\title{
PRESENT SCENARIO IN VISION LOSS- NEUROLOGICAL CAUSES AND MAGNITUDE OF THE PROBLEM OF CHRONIC VISUAL LOSS- AN EXPERIENCE FROM A TERTIARY CARE HOSPITAL
}

\author{
Ramachandra Ramesh ${ }^{1}$, Arun Jyothi Gaddameedi², Souris Kondaveti ${ }^{3}$
}

${ }_{1}^{1}$ Associate Professor, Department of Neurology, OMC, Hyderabad, Telangana, India.

${ }^{2}$ Senior Resident, Department of Pharmacology, OMC, Hyderabad, Telangana, India.

${ }^{3}$ Assistant Professor, Department of Pharmacology, OMC, Hyderabad, Telangana, India.

\section{ABSTRACT}

\section{BACKGROUND}

Ocular causes are the commonest causes of visual loss in general population. ${ }^{1}$ Though neurological causes of visual loss form a minor proportion, they are important to be recognised because many of them are potentially treatable if diagnosed and managed appropriately. ${ }^{2,3}$

Hence, this study was taken up with the following objectives- 1 . to evaluate the various causes of visual impairment presenting to the Neurology clinic and 2. To determine the magnitude of the problems of chronic visual loss.

\section{MATERIALS AND METHODS}

This was a descriptive study performed over a period of 2 years (Jan 2004 to Oct 2006). 48 patients of either gender aged 18 yrs. and above who satisfied the inclusion and exclusion criteria were included in the study.

\section{RESULTS}

Majority of patients had acute visual loss, 20 patients (41.66\%) followed by chronic visual loss (17 patients, 35.41\%). In majority of patients ( $n=27$ patients, $56.25 \%$ ), demyelinating optic neuropathy was found to be the cause. In majority of patients with chronic visual loss ( $\mathrm{n}=17$ patients, $35.41 \%)$, the cause was not known. Patients who had demyelinating optic neuropathy received steroids and majority of them $(n=12)$ received 3 days of dexamethasone followed by 11 days of oral prednisolone.

\section{CONCLUSION}

The majority of patients with neurogenic vision loss had diseases of anterior visual pathway. Chronic visual loss with no defined cause was observed, but in 2 patients demyelinating optic neuropathy was seen. The patients with acute and subacute visual loss with and without any identifiable cause were empirically treated with steroids if not contraindicated otherwise. Intravenous methylprednisolone for 3 days followed by 11 days of oral prednisolone is the best mode of treatment for demyelinating optic neuropathy. Recurrence of optic neuropathy was not seen during follow-up. Patients with severe impairment of vision and late presentation had poor prognosis in this study.

\section{KEY WORDS}

Chronic Visual Loss, Sudden Visual Loss, Demyelinating Optic Neuropathy, Dexamethasone.

HOW TO CITE THIS ARTICLE: Ramesh R, Gaddameedi AJ, Kondaveti S. Present scenario in vision loss- neurological causes and magnitude of the problem of chronic visual loss- an experience from a tertiary care hospital. J. Evolution Med. Dent. Sci. 2018;7(28):3195-3198, DOI: 10.14260/jemds/2018/719

\section{BACKGROUND}

Visual impairment and visual loss are common presentations. Ocular causes are the commonest causes of visual loss in general population including cataract, glaucoma and that related to diabetes mellitus. ${ }^{1}$

Though neurological causes ${ }^{2,3}$ of visual loss form a minor proportion they are important to be recognised, because many of them are potentially treatable if diagnosed and managed appropriately. As many of them are initially seen by an ophthalmologist or a general physician, there is a delay in such cases attending to a neurologist. Hence, it is important to know the neurological disorders presenting with monosymptomatic visual loss, not only by neurologist but also by ophthalmologists, general physicians and primary

'Financial or Other Competing Interest': None.

Submission 22-05-2018, Peer Review 25-06-2018,

Acceptance 01-07-2018, Published 09-07-2018.

Corresponding Author:

Arun Jyothi Gaddameedi,

H. No. 1-29-1, Subashnagar, Trimulghuy,

Secunderabad-500015, Telangana, India.

E-mail: ajjyothi9@gmail.com

DOI: $10.14260 /$ jemds $/ 2018 / 719$ care doctors. Good cooperation between the faculties is indeed necessary to refer the case to the concerned specialist for a timely action.

Hence, this study was taken up with the objective to evaluate the various causes of visual impairment presenting to the Neurology clinic and the magnitude of the problem of chronic visual loss.

\section{MATERIALS AND METHODS Study Subjects}

This was a descriptive study performed during the period of 2 years (Jan 2004 to Oct 2006). 48 patients of either gender aged 18 yrs. and above who met the eligibility standards, i.e. patients who had unilateral, bilateral or field defects which had been acute or subacute or continual have been covered in the study. All the patients were subjected to detailed history taking and were examined in detail. Visual acuity was tested with Rosenbaum's pocket vision screener. Visual fields were examined by bedside confrontation method. Colour vision was tested by Ishihara's colour plates. Fundus was examined by direct ophthalmoscopy. The findings were confirmed by an ophthalmologist. Patients with ocular cause of visual impairment and other neurological complaint other than the presence of mild headache were excluded from the study. 


\section{Study Procedure}

Written informed consent was taken from all the subjects after a full explanation of aims, procedures and risks of the study. The study was approved by the Institutional Ethics Committee and conducted in conformity with the Declaration of Helsinki.

Routine blood parameters were done in all the patients. All the patients were subjected to pattern shift visual evoked potential study. CSF analysis was done in 10 patients who presented with chronic visual loss. Imaging was done in all the patients. MRI brain was done including the orbital cuts in 12 patients. CT scan brain was done in the rest due to financial constraint since MRI scan facility is not available free of cost. The patient's diagnosis arrived and was treated appropriately.

The data was analysed systematically and the results were derived.

\section{RESULTS}

In our study, majority of patients fell into the age group of 1830 years (32 patients, 66.67\%) followed by $31-40$ (8 patients, $16.66 \%$ ) and $41-50$ (7 patients, 14.58\%). Only 1 patient $(2.08 \%)$ was in the age group of $51-60$ years. $2 / 3^{\text {rds }}$ of the patients were less than 30 years of age indicating that it was commonly seen in the younger age category. There was not much of difference in the incidence between males and females in our study (25 females (52.08\%)/ 23 males $(47.92 \%))$.

\begin{tabular}{|c|c|c|c|c|}
\hline Features & \multicolumn{3}{|c|}{ No. of Patients } & \multirow{2}{*}{ total } \\
\hline $\begin{array}{c}\text { Category } \\
\text { of Visual } \\
\text { Loss }\end{array}$ & $\begin{array}{c}\text { Field } \\
\text { Defect }\end{array}$ & Bilateral & Unilateral & \\
\hline Sudden & 2 & 1 & 1 & 4 \\
\hline Acute & 0 & 5 & 15 & 20 \\
\hline Subacute & 0 & 5 & 2 & 7 \\
\hline Chronic & 1 & 15 & 1 & 17 \\
\hline Table 1. Mode of Onset of Visual Loss and Character of \\
Visual Loss \\
\hline
\end{tabular}

Majority of patients had acute visual loss, 20 patients (41.66\%). In this category, 15 patients $(75 \%)$ had unilateral visual loss and 5 patients (25\%) had bilateral visual loss suffering with bilateral sequential optic neuropathy.

The next peak was formed by the patients who had chronic visual loss (17 patients, 35.41\%), in which 15 patients $(88.23 \%)$ had bilateral visual loss, 1 patient $(5.88 \%)$ had unilateral visual loss and 1 patient (5.88\%) had field defect. In 15 patients who had bilateral visual loss, 10 patients had bilateral simultaneous visual loss and 5 patients had involvement of one eye followed by the other. The patient who had unilateral visual loss had history of fever preceding the onset of visual loss. The patient who had field defect had a bitemporal field defect.

In the category of subacute visual loss $(n=7), 5$ patients (71.28\%) had bilateral visual loss and 2 patients $(28.57 \%)$ had unilateral visual loss. Among the 5 patients who had bilateral visual loss, 3 had bilateral sequential optic neuropathy and 2 patients had bilateral recurrent optic neuropathy.

In the category of sudden visual loss $(n=4) 2$ patients $(50 \%)$ had field defects, 1 patient $(25 \%)$ had bilateral visual impairment and 1 patient (25\%) had unilateral visual impairment. In the field defects, one patient had left homonymous hemianopia and the other had right homonymous hemianopia. The patient who had bilateral visual impairment initially had left homonymous hemianopia 2 years back due to an ischaemic stroke causing infarct in right occipital lobe and presented to us with total loss of vision as a result of a fresh ischaemic stroke causing infarct in the left occipital lobe. The patient who had unilateral visual impairment had an altitudinal field defect suggesting ischaemia of the anterior visual pathway. All the patients were above 40 years of age and had vascular risk factors. On follow-up, they did not have any improvement in vision.

\begin{tabular}{|c|c|}
\hline Degree of Visual Impairment & No. of Patients \\
\hline Normal & 3 \\
\hline Diminished visual acuity & 2 \\
\hline Limited to finger counting & 23 \\
\hline Limited to light perception & 18 \\
\hline No perception of light & 2 \\
\hline \multicolumn{2}{|c|}{ Table 2. Degree of Visual Impairment } \\
\hline
\end{tabular}

\section{Pupillary Light Reflexes}

In the category of sudden visual loss $(n=4), 3$ patients $(75 \%)$ had normal pupillary light reflexes, 1 patient $(25 \%)$ had impairment of direct and indirect light reflexes.

In the category of acute visual loss $(n=20)$, majority i.e. 14 patients $(70 \%)$ had impairment of direct and indirect light reflexes and 6 patients (30\%) had relative afferent pupillary defect which emphasises the fact that one should look for RAPD by swinging flash light test when the direct and indirect light reflexes are normal.

In the category of subacute visual loss $(n=7), 6$ patients (85.71\%) had impairment of direct and indirect light reflexes and 1 patient (14.28\%) had relative afferent pupillary defect.

In the category of chronic visual loss $(n=17)$, majority i.e. 13 patients $(76.47 \%)$ had impairment of direct and indirect light reflexes, 3 patients (17.64\%) had normal pupillary light reflexes and 1 patient (5.88\%) had RAPD who had demyelinating optic neuropathy.

\begin{tabular}{|c|c|c|c|}
\hline Features & \multicolumn{3}{|c|}{ Fundus and No. of Patients } \\
\hline $\begin{array}{c}\text { Category of } \\
\text { Visual Loss }\end{array}$ & Normal & Optic Atrophy & Papillitis \\
\hline Sudden & 3 & 1 & 0 \\
\hline Acute & 4 & 0 & 16 \\
\hline Subacute & 1 & 0 & 6 \\
\hline Chronic & 2 & 14 & 1 \\
\hline \multicolumn{3}{|c|}{ Table 3. Fundus Examination Details } \\
\hline
\end{tabular}

Since majority of the above patients had an abnormal fundus in the form of papillitis, which can closely mimic papilloedema it is almost mandatory to depend on degree of visual loss and pupillary light reflexes in differentiating one from the other than depending only on the fundus findings.

\begin{tabular}{|c|c|c|c|c|}
\hline Features & \multicolumn{4}{|c|}{ Visual Evoked Potentials } \\
\hline $\begin{array}{c}\text { Category of } \\
\text { Visual Loss }\end{array}$ & Normal & $\begin{array}{c}\text { Poor Wave } \\
\text { Forms }\end{array}$ & $\begin{array}{c}\text { Amplitude } \\
\text { Loss }\end{array}$ & $\begin{array}{c}\text { Prolonged } \\
\text { P100 Lat }\end{array}$ \\
\hline Sudden & 3 & 1 & 0 & 0 \\
\hline Acute & 0 & 5 & 1 & 14 \\
\hline Subacute & 0 & 0 & 2 & 5 \\
\hline Chronic & 4 & 4 & 7 & 2 \\
\hline \multicolumn{5}{|c|}{ Table 4. Visual Evoked Potentials } \\
\hline
\end{tabular}




\begin{tabular}{|c|c|c|c|c|}
\hline $\begin{array}{c}\text { Sudden } \\
\text { Visual Loss } \\
(n=4)\end{array}$ & \multicolumn{2}{|c|}{$\begin{array}{l}\text { Occipital Lobe } \\
\text { Infarcts } \\
\text { (3 Patients) }\end{array}$} & \multicolumn{2}{|c|}{$\begin{array}{c}\text { Anterior Ischaemic } \\
\text { Optic Neuropathy } \\
\text { (1 Patient) }\end{array}$} \\
\hline $\begin{array}{c}\text { Acute and } \\
\text { Subacute } \\
\text { Visual Loss } \\
(\mathrm{n}=27)\end{array}$ & \multicolumn{4}{|c|}{ Demyelinating Optic Neuropathy } \\
\hline $\begin{array}{c}\text { Chronic Visual } \\
\text { Loss ( } \mathrm{n}=17)\end{array}$ & $\begin{array}{c}\text { No defined } \\
\text { cause, } \\
11 \text { patients } \\
(64.7 \%)\end{array}$ & \multicolumn{2}{|c|}{\begin{tabular}{|c} 
Demyelinating \\
optic neuropathy, \\
2 patients \\
$(11.76 \%)$
\end{tabular}} & $\begin{array}{c}\text { Tumour, } \\
4 \text { patients } \\
(23.5 \%)\end{array}$ \\
\hline \multicolumn{5}{|c|}{ Table 5. Causes of Visual Loss } \\
\hline
\end{tabular}

\section{Treatment of Underlying Cause}

Patients who had demyelinating optic neuropathy, who received steroids fell in three groups. There were some differences between the groups in the short-term outcome in terms of visual improvement.

\section{Group 1}

(Methylprednisolone group, $n=10$ ). This group received 3 days of intravenous methylprednisolone followed by oral prednisolone for 11 days. The follow-up was done at 1 and 6 months after starting the treatment. 8 patients improved in 1 month and 2 patients improved in 6 months. All the patients showed some improvement in this study group.

\section{Group 2}

(Dexamethasone group, $\mathrm{n}=12$ ). This group received 3 days of dexamethasone followed by 11 days of oral prednisolone. 7 patients improved in 1 month and 5 patients improved in 6 months. Though improvement was seen in all the patients, $41.66 \%$ of patients had improvement only at 6 months compared to $20 \%$ in Group 1.

\section{Group 3}

(Oral prednisolone group, $n=7$ ). This group received oral prednisolone for a period of 14 days. 2 out of 7 patients showed improvement at 6 months and 2 patients did not show any improvement. The above results indicate that all the Group 1 and Group 2 patients improved, though Group 1 patients had more rapid visual improvement. Some of the patients $(n=2)$ in Group 3 did not show improvement and the degree of improvement was also less when compared to Group 1 and 2 . All of these were not statistically significant.

\section{DISCUSSION}

The present study was conducted in 48 patients to evaluate the various causes of visual impairment presenting to the Neurology clinic and the magnitude of the problem of chronic visual loss. The study population was homogenous.

In our study it was observed that there was not much of difference in the incidence between males and females, except for a slight preponderance in females $(25$ females (52.08\%)/ 23 males (47.92\%)). Most studies show female-tomale ratio of 3: 2.4

In a study by Rajesh Verma et al, 5 in which 64 cases were enrolled. 54 cases were due to diseases of anterior visual pathway and rest 10 had cortical vision loss. It was observed that the commonest of visual impairment was tubercular meningitis- 15 (23.8\%) followed by isolated optic neuritis- 12 (19\%), multiple sclerosis- 4 (6.3\%), neuromyelitis optica- 5 (7.9\%), non-arteritic ischaemic optic neuropathy, ischaemic optic neuropathy complicating cavernous sinus thrombosis, cryptococcal meningitis, malignant infiltration of optic nerve, Crouzon's syndrome, calvarial thickening and traumatic occipital gliosis- 1 (1.6\%) case each, idiopathic intracranial hypertension, pituitary adenoma, acute disseminated encephalomyelitis, posterior reversible leukoencephalopathy- 3 (4.8\%) cases each, cortical venous thrombosis 5 (7.9\%), subacute sclerosing panencephalitis- 4 $(6.3 \%)$ cases.

In our study, we have observed that demyelinating optic neuropathy to be the most common neurological cause of visual impairment, which are in accordance with the study mentioned above.

American Foundation of Blindness stated that ${ }^{6}$ during the last decade vision loss caused by damage to the brain rather than by conditions or diseases of the eye has been the focus of increasing attention.

In our study, we have observed that recurrence of optic neuropathy was not seen in the short-term follow-up spanning 6 months, but in a study by Pirko et al stated longterm studies have shown that recurrence was not uncommon in patients with an abnormal MRI. ${ }^{7}$

Schmiedel J et al ${ }^{8}$ stated mitochondrial cytopathies can have optic atrophy as an isolated manifestation in our study. An attempt was made to identify it in these cases by doing a muscle biopsy for ragged red fibers. It was done in 4 patients in whom muscle biopsy was negative for ragged red fibers.

In a study by John $\mathrm{H}$ Pula et $\mathrm{al},{ }^{9}$ it was observed that sudden visual loss was due to vascular emboli and infarcts. Even in our study, the cause of sudden visual loss was occipital lobe infarcts, which was in accordance with the above-mentioned study.

In a study by TD Myers et al,10 in Northwest England it was found that significantly more neurologists (55\%) than ophthalmologists (9\%) chose to treat with intravenous methylprednisolone $(\mathrm{p}<0.005)$. Significantly, more ophthalmologists $(64 \%)$ than neurologists $(32 \%)$ chose not to give steroids $(\mathrm{p}<0.025)$. Oral prednisolone alone was rarely selected for treatment.

In our study, oral prednisolone alone was used in less patients which was in accordance with the above-mentioned study.

\section{CONCLUSION}

Several aetiologies of neurogenic vision loss were observed in this study. The majority of patients with neurogenic vision loss had diseases of anterior visual pathway. Among optic neuropathies, the most important aetiologies were demyelinating diseases. In the demyelinating group, bilateral visual loss was seen. On the other hand, chronic visual loss was due to demyelinating optic neuropathy (seen in two patients). The patients with acute and subacute visual loss without any identifiable cause were empirically treated with steroids if not contraindicated otherwise. Intravenous methylprednisolone for 3 days followed by 11 days of oral prednisolone is the best mode of treatment for demyelinating optic neuropathy. Recurrence of optic neuropathy was not seen during follow-up. Patients with severe impairment of vision and late presentation had poor prognosis in this study. 


\section{REFERENCES}

[1] World Health Organization report. Magnitude and causes of visual impairment. 2004.

[2] Brazis PW, Masdeu JC, Biller J. Localization in clinical neurology. $4^{\text {th }}$ edn. Lippincott Williams \& Wilkins 2001.

[3] Bradley WG, Daroff RB, Fenichel GM, et al. Neurology in clinical practice. $4^{\text {th }}$ edn. Butterworth-Heinemann 2004.

[4] Optic Neuritis Study Group. The clinical profile of optic neuritis. Experience of the Optic Neuritis Treatment Trial. Arch Ophthalmol 1991;109(12):1673-8.

[5] Verma R, Gupta M, Chaudhari TS. Neurogenic vision loss: causes and outcome. An experience from a tertiary center in Northern India. J Neurosci Rural Pract 2014;5(4):340-8.
[6] Cortical Visual Impairment, Traumatic Brain Injury, and Neurological...www.afb.org > Living with Vision Loss > Eye Conditions

[7] Pirko I, Blauwet LA, Lesnick TG, et al. The natural history of recurrent optic neuritis. Arch Neurol 2004;61(9):1401-5.

[8] Schmiedel J, Jackson S, Schafer J, et al. Mitochondrial cytopathies. J Neurol 2003;250(3):267-77.

[9] Pula JH, Kwan K, Yuen CA, et al. Update on the evaluation of transient vision loss. Clin Ophthalmol 2016;10:297-303.

[10] Myers TD, Smith JR, Wertheim MS, et al. Use of corticosteroid sparing systemic immunosuppression for treatment of corticosteroid dependent optic neuritis not associated with demyelinating disease. $\mathrm{Br}$ J Ophthalmol 2004;88(5):673-80. 